\title{
Microcomputed Tomography Calibration Using Polymers and Minerals for Enamel Mineral Content Quantitation
}

\author{
Asma Alyahya $^{a} \quad$ Athbi Alqareer ${ }^{a}$ Michael Swain ${ }^{b, c}$ \\ ${ }^{a}$ Department of Developmental and Preventive Sciences, Faculty of Dentistry, Kuwait University, Safat, Kuwait; \\ ${ }^{b}$ Department of Bioclinical Sciences, Faculty of Dentistry, Kuwait University, Safat, Kuwait; ${ }^{\mathrm{C} D o n}$ State Technical \\ University, Rostov-on-Don, Russia
}

\section{Significance of the Study}

- This study developed calibration standards (CSs) that are readily available for clinical researchers for the quantitation of enamel mineral content. It employed polymers and minerals as CSs in lieu of expensive and difficult-to-fabricate traditional standards. This simple method could encourage clinicians to use this technology to expand knowledge in the field of caries research.

\section{Keywords}

Microcomputed tomography · Calibration standards .

Minerals · Polymers · Early enamel lesions

\begin{abstract}
Objective: The aim of this paper was to develop calibration standards (CSs) that are readily available for clinical researchers for the quantitation of enamel mineral content. Method: Polyethylene terephthalate (PET), acetal, polyphenylene sulfide (PPS), selenite, Egyptian alabaster, aragonite, and fluorite were fashioned into discs, and their densities were measured and stacked for microcomputed tomography examination. Frame averaging, flat-field correction, pre-filtration, and beam-hardening correction were applied. CSs were checked for homogeneity. The linear relationship between the mean greyscale value (GSV) of each disc and its physi-
\end{abstract}

cally calculated density was explored, and reproducibility was tested. A calibration function was established and then validated using a bovine enamel disc and sound enamel of extracted human premolar teeth. Results: Measured densities were PET $\left(\rho=1.38 \mathrm{~g} / \mathrm{cm}^{3}\right)$, acetal $\left(\rho=1.41 \mathrm{~g} / \mathrm{cm}^{3}\right)$, PPS $\left(\rho=1.64 \mathrm{~g} / \mathrm{cm}^{3}\right)$, selenite $\left(\rho=2.24 \mathrm{~g} / \mathrm{cm}^{3}\right)$, Egyptian alabaster $\left(\rho=2.7 \mathrm{~g} / \mathrm{cm}^{3}\right)$, aragonite $\left(\rho=2.72 \mathrm{~g} / \mathrm{cm}^{3}\right)$, and fluorite $(\rho=$ $3.11 \mathrm{~g} / \mathrm{cm}^{3}$ ). Examination of the profile sections of CSs confirmed the uniformity of GSVs with minimal beam-hardening effect. A squared Pearson correlation coefficient of $R^{2}=0.994$ was determined between the mean GSV of each CS and its calculated density and was reproduced at different settings with $R^{2}>0.99$. A linear regression equation of density (y) versus GSV ( $\mathrm{x}$ ) was established using the least squares regression equation method. The estimated density of the bovine enamel disc $\left(2.48 \mathrm{~g} / \mathrm{cm}^{3}\right)$ showed high accuracy when compared to the physically measured value $\left(2.45 \mathrm{~g} / \mathrm{cm}^{3}\right)$. The

\begin{tabular}{ll}
\hline KARGER & $\begin{array}{l}\text { (c) } 2019 \text { The Author(s) } \\
\text { Published by S. Karger AG, Basel }\end{array}$ \\
$\begin{array}{l}\text { E-Mail karger@karger.com } \\
\text { www.karger.com/mpp }\end{array}$ & $\begin{array}{l}\text { This is an Open Access article licensed under the Creative Commons } \\
\text { Attribution-NonCommercial-4.0 International License (CC BY-NC) } \\
\text { (http://www.karger.com/Services/OpenAccessLicense), applicable to } \\
\text { the online version of the article only. Usage and distribution for com- } \\
\text { mercial purposes requires written permission. }\end{array}$
\end{tabular}

Asma Alyahya

Department of Developmental and Preventive Sciences

Faculty of Dentistry, Kuwait University, P.O. Box 24923

Safat 13110 (Kuwait)

E-Mail asma@hsc.edu.kw 
relative error was $1.2 \%$. Densities of sound enamel in the extracted human premolar teeth were $2.6-3.1 \mathrm{~g} / \mathrm{cm}^{3}$. Conclusions: This is a simple, valid, and reproducible method to quantitate enamel mineral content. This simple, yet accurate system could be used to expand knowledge in the field of enamel caries research.

(c) 2019 The Author(s)

Published by S. Karger AG, Basel

\section{Introduction}

Microcomputed tomography (micro-CT) technology, and more recently, nanocomputed tomography technology, enable three-dimensional, nondestructive imaging of tooth structures revealing microscopic details [1-4]. This approach has been used to study the demineralization and remineralization of teeth [5-11]. It can also be used to study before and after comparisons of different dental treatments [12-14]. However, as other methodologies, micro-CT imaging has its limitations and challenges [15]. A potentially useful application of micro-CT imaging is the determination of mineral density based on reconstructed greyscale values (GSVs) of micro-CT image voxels. While the GSVs of structures visible in microCT scans have been shown to be proportional to the mineral density of scanned materials [16-18], the calibration of these values is a prerequisite for valid quantitation. With the possibility of machine $\mathrm{X}$-ray source and detector sensitivity drift and setting variations between scans, researchers need a method for external calibration between and within their scans [19].

The focus of this study was to develop calibration standards (CSs) that are handy for clinical researchers to use for quantitating enamel mineral content. Hence, this communication covers only enamel calibration, and it summarizes some of the challenges encountered with the existing calibration methods. Metals, such as aluminum, have been traditionally used to calibrate microradiography and micro-CT $[7,20,21]$. An aluminum step wedge has been used to calibrate beam attenuation to enable accurate mineral content calculations. The drawback of this technique is the fact that commercial desktop micro-CT systems utilize polychromatic radiation where the beam has altered X-ray energies, leading to different attenuations of the same material [16]. Another popular way to calibrate GSVs is the use of CSs, which are scanned together with the specimens. Pure pressed and sintered hydroxyapatite standards in solid form were proven to be spatially homogeneous $[22,23]$. However, they are difficult to fabricate [23]. Other CSs made from hydroxyapa- tite/resin mixtures typically cover the density range useful for studying bone, dentine, and other tissues with low mineral density but may not be suitable for tooth enamel research as higher densities are difficult to achieve and are often nonhomogeneous and fragile [19].

Our intention in this study was to find easy-to-fabricate materials for clinical researchers to use as CSs for research on enamel caries. These CS materials should have densities within the range of $1.52-3.14 \mathrm{~g} / \mathrm{cm}^{3}$.

\section{Materials and Methods}

Seven solid materials were tested: polyethylene terephthalate (PET), acetal, polyphenylene sulfide (PPS), selenite, Egyptian alabaster, aragonite, and fluorite. They were fashioned into discs of a $9-\mathrm{mm}$ diameter and $1.5-\mathrm{mm}$ height to fit into a $2.0-\mathrm{mL}$ vial (Nalgene ${ }^{\circledR}$ cryogenic vials). A digital caliper (accurate to $0.0001 \mathrm{~mm}$; Mitutoyo Corporation, Aurora, IL, USA) was used to measure the dimensions of each disc to calculate the disc volume using the cylinder volume formula $\left(\mathrm{V}=\pi r^{2} \mathrm{~h}\right)$. Five readings from different points on the discs were averaged to calculate the mean diameter and height. Mass was determined using an electronic, analytic scale (accurate to $0.0001 \mathrm{~g}$; Shimadzu Corporation, Tokyo, Japan). The density of each disc was calculated using the formula $(\rho=\mathrm{m} /$ $\mathrm{V}$, where $\mathrm{m}=$ mass and $\mathrm{V}=$ volume).

The CSs were stacked in a safe-lock, 2 -mL vial and then stabilized with sticky wax on the rotation mount of the micro-CT system (Phoenix nanotom ${ }^{\circledR} \mathrm{m}$; GE, Germany) that rotates around an axis perpendicular to the beam direction (Fig. 1a).X-rays were generated at $110 \mathrm{kV}$ and $160 \mu \mathrm{A}$, creating 2,000 two-dimensional projections over a 360-degree rotation of the specimen with a voxel size of 13.3 $\mu \mathrm{m}$. A $0.25-\mathrm{mm}$-thick copper filter was placed in the path of the beam to restrict spectral bandwidth of the polychromatic radiation from the tungsten anode. Three-frame averaging was applied. Acquired images were 3,052 $\times 2,400$ pixels in resolution. On average, the acquisition time was $105 \mathrm{~min}$. The created $2 \mathrm{D}$ images were $3 \mathrm{D}$ reconstructed using Phoenix Datosx CT Software (GE Sensing \& Inspection Technologies GmbH, Wunstorf, Germany) and transferred to VGStudio Max 3.0 (Volume Graphics, Heidelberg, Germany) for visualization, segmentation, and analysis. The beamhardening correction module of the Phoenix Datosx CT Software was applied during reconstruction (set at 8). These settings were optimized based on pilot experiments. The Phoenix nanotom ${ }^{\circledR} \mathrm{m}$ machine also did an automatic beam-hardening correction, which aided in minimizing this artifact. To verify the homogeneity and uniformity of the CSs, a centered, cross-sectional 2D image was taken from the generated data set, across each CS. A Profile window was created, and a line was drawn across the CS's diameter creating a graph of distance $(\mathrm{x})$ versus GSV (y). The created graph was also used to check for presence of beam hardening. Standard deviations were used to reflect the amount of noise present.

A representative volume chosen from the center of each CS was selected using ellipse selection mode and was dragged into the third dimension. A region of interest (ROI) was then created. Under the Porosity/Inclusion Analysis module, a defect analysis was performed for each ROI representing CS to obtain the mean and the standard deviation of GSV of each CS. The linear relationship be- 
Fig. 1. CSs setup for micro-CT examination. a The seven tested CSs (from bottom to top): A: PET; B: acetal; C: PPS; D: selenite; E: Egyptian alabaster; F: aragonite; and G: fluorite. $\mathbf{b}$ The three chosen CSs (A: PET; D: selenite; and G: fluorite) scanned with an extracted human tooth.

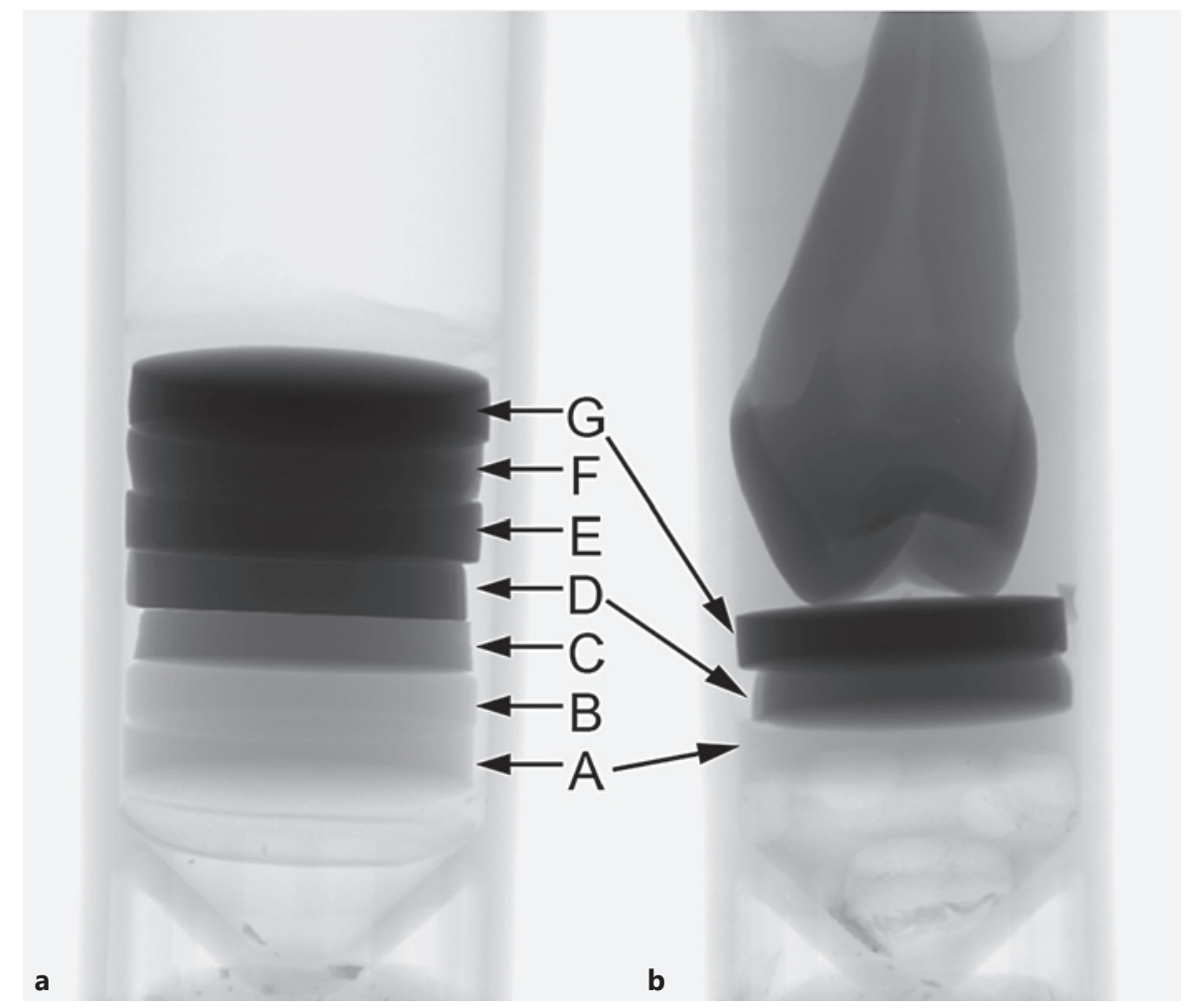

tween the mean GSV of each disc and its calculated density was thereafter explored using the squared Pearson correlation coefficient $\left(R^{2}\right)$. The reproducibility of the obtained linear relationship at different energy levels was tested through fixing the current at 160 $\mu \mathrm{A}$ and varying the voltage from 60 to $110 \mathrm{kV}$. A scatter plot was created by plotting the mean GSV of each CS (x) against its' calculated density (y), and a calibration function was established using the least squares regression equation method ( $\mathrm{y}=$ slope $\mathrm{x}+$ intercept).

Validation of the calibration function was done by estimating the density of a bovine enamel disc based on its average CT-determined GSV and comparing it to the physically measured value. The bovine enamel disc was obtained from the labial surface of an extracted bovine central incisor. A cylindrical piece of enamel with underlying dentin was cut using an 8 - $\mathrm{mm}$-diameter diamond core drill bit. Dentin was then removed, and the disc was flattened by wet sanding on 320 grit wet/dry sand paper. The bovine enamel disc was scanned on top of the CSs under the same experimental conditions that the calibration function was developed. The relative error for the CT-determined density was calculated.

Validation of the calibration function by estimating the mineral density of sound human enamel was done on 10 unrestored, non-cavitated, extracted human premolars with closed apices. Teeth with developmental enamel defects were excluded. Extracted teeth were collected from several dental clinics and were stored in saline solution-containing thymol granules following extraction. The extracted teeth bore no information regarding the patients' gender nor age. To streamline the calibration process and maximize space utilization by tooth samples, only three of the CSs, which best fitted the calibration function and covered the required density range, were scanned with each sample. This enabled further voxel size reduction to achieve higher resolution. The three CSs (fluorite, selenite, and PET) with an extracted human tooth were placed in a vial, which was stabilized on the rotating mount of the CT-machine using sticky wax (Fig. 1b). The extracted tooth was kept humidified by immersion in saline solution and stabilized by compressing a piece of wax between its root and the tube's walls. A ROI containing the entire volume of enamel was created using the "surface determination" function and was refined with the "draw" tool to exclude the fluorite disc from the ROI since enamel and fluorite overlap in density. Under the Porosity/Inclusion Analysis module, a defect analysis was performed on the created ROI containing only enamel to obtain descriptive statistics of GSVs (Fig. 2). X-rays were generated at $110 \mathrm{kV}$ and $160 \mu \mathrm{A}$, creating 3,000 two-dimensional projections over a 360-degree rotation of the specimen with a voxel size of $7.1 \mu \mathrm{m}$. Pre-filtration with a copper filter was used. Three-frame averaging was also applied. On average, the acquisition time was $158 \mathrm{~min}$.

\section{Results}

The physically measured densities for the different CSs were PET $\left(\rho=1.38 \mathrm{~g} / \mathrm{cm}^{3}\right)$, acetal $\left(\rho=1.41 \mathrm{~g} / \mathrm{cm}^{3}\right)$, PPS $\left(\rho=1.64 \mathrm{~g} / \mathrm{cm}^{3}\right)$, selenite $\left(\rho=2.24 \mathrm{~g} / \mathrm{cm}^{3}\right)$, Egyptian alabaster $\left(\rho=2.7 \mathrm{~g} / \mathrm{cm}^{3}\right)$, aragonite $\left(\rho=2.72 \mathrm{~g} / \mathrm{cm}^{3}\right)$, and fluorite $\left(\rho=3.11 \mathrm{~g} / \mathrm{cm}^{3}\right)$. 



Fig. 2. Defect analysis performed on created ROI containing only enamel. Descriptive statistics of GSVs were calculated for the entire volume of intact enamel. a Top-view workplace 2D window displaying defect analysis performed on extracted enamel (area colored red; color in online version only). Surface determination function enabled us to define intact enamel and thus early enamel lesion present was excluded from analysis. $\mathbf{b}$ Same as $\mathbf{a}$, but a frontview workplace $2 \mathrm{D}$ window. c Same as a, but a right-view workplace $2 \mathrm{D}$ window. $\mathbf{d}$ Same as a, but $3 \mathrm{D}$ window.

profile window of the same fluorite disc, under the same settings, with $\mathrm{Cu}$ pre-filtration but without applying the beam-hardening correction module. The addition of a $\mathrm{Cu}$ filter reduced the beam-hardening effect. The standard deviation of the created interval in Figure 3c, 2,084 AU, was significantly less than the standard deviation in Figure 3b, $4232 \mathrm{AU}$.

Table 1 summarizes the descriptive statistics of the GSVs of the CSs derived from their representative volumes. The results showed that as the density of the material increases, the standard deviation of the associated GSVs also increases. Figure $4 \mathrm{a}$ is a scatter plot that displays the linear relationship between the mean GSV and the calculated density for the seven CSs. A squared Pearson correlation coefficient of $R^{2}=0.994$ was determined. The linear relationship was reproduced at different settings. Table 2 lists the regression data obtained, slope and intercept, at the different voltage set- 
Fig. 3. Influence of pre-filtration and beamhardening correction during reconstruction. a Profile window of fluorite disc scanned with radiation energy $(110 \mathrm{kV}, 160$ $\mu \mathrm{A}$ ) with the application of both a $\mathrm{Cu}$ filter and the beam-hardening correction module during the reconstruction process. b Same as a, but without application of a $\mathrm{Cu}$ filter nor the beam-hardening correction module. c Same as a, but with Cu prefiltration and without application of the beam-hardening correction module.

Micro-CT Calibration for Enamel Caries Research
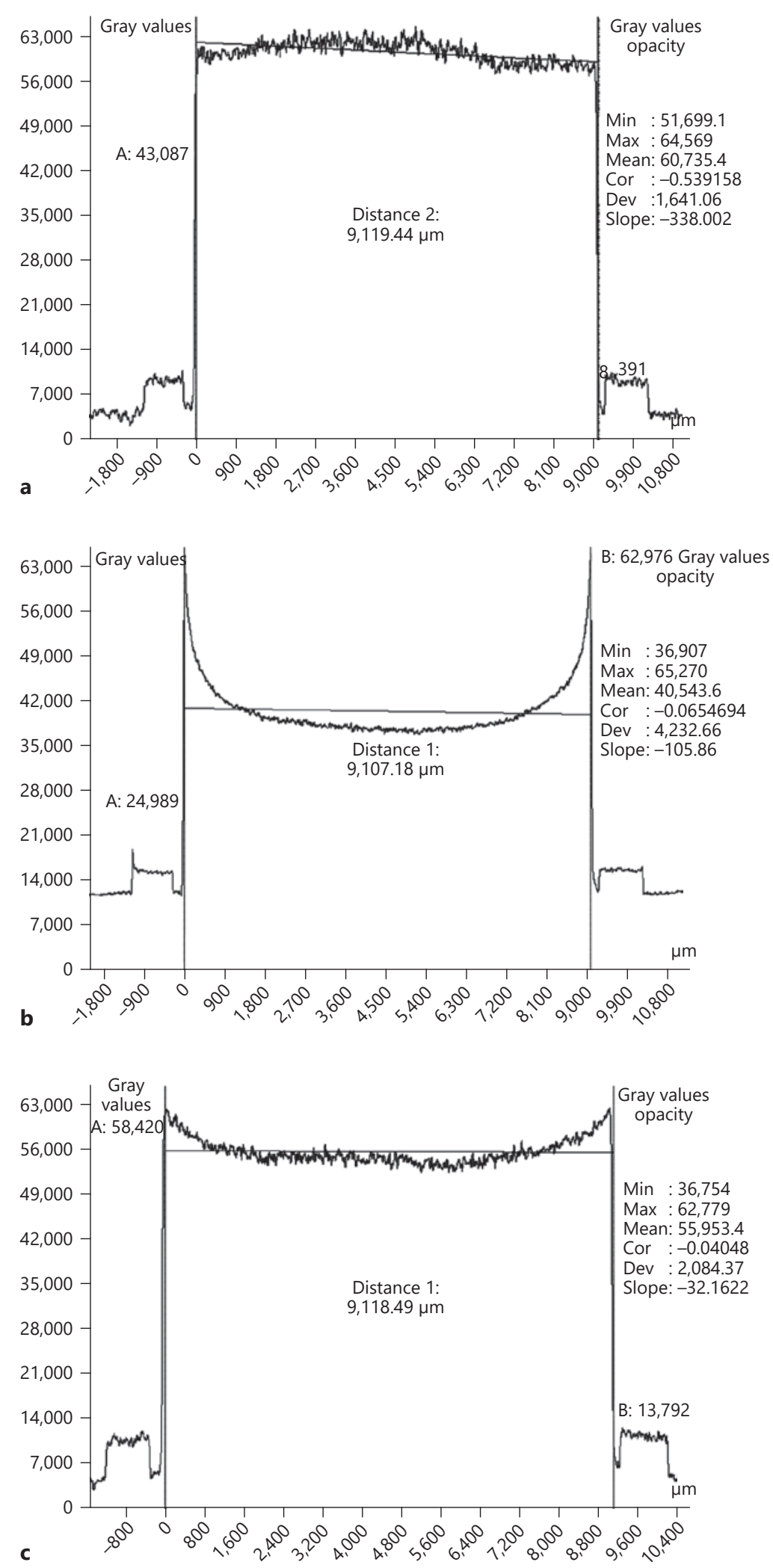

Med Princ Pract 2019;28:247-255 
Fig. 4. Test of linearity between the mean GSVs versus physically calculated density. a Scatter plot of mean GSV versus calculated density for the seven CSs (A: PET; B: acetal; C: PPS; D: selenite; E: Egyptianalabaster; F: aragonite; and G: fluorite). Squared Pearson correlation coefficient and calibration function are displayed. b Same as a, but for the three chosen CSs (A: PET; D: selenite; and G: fluorite).
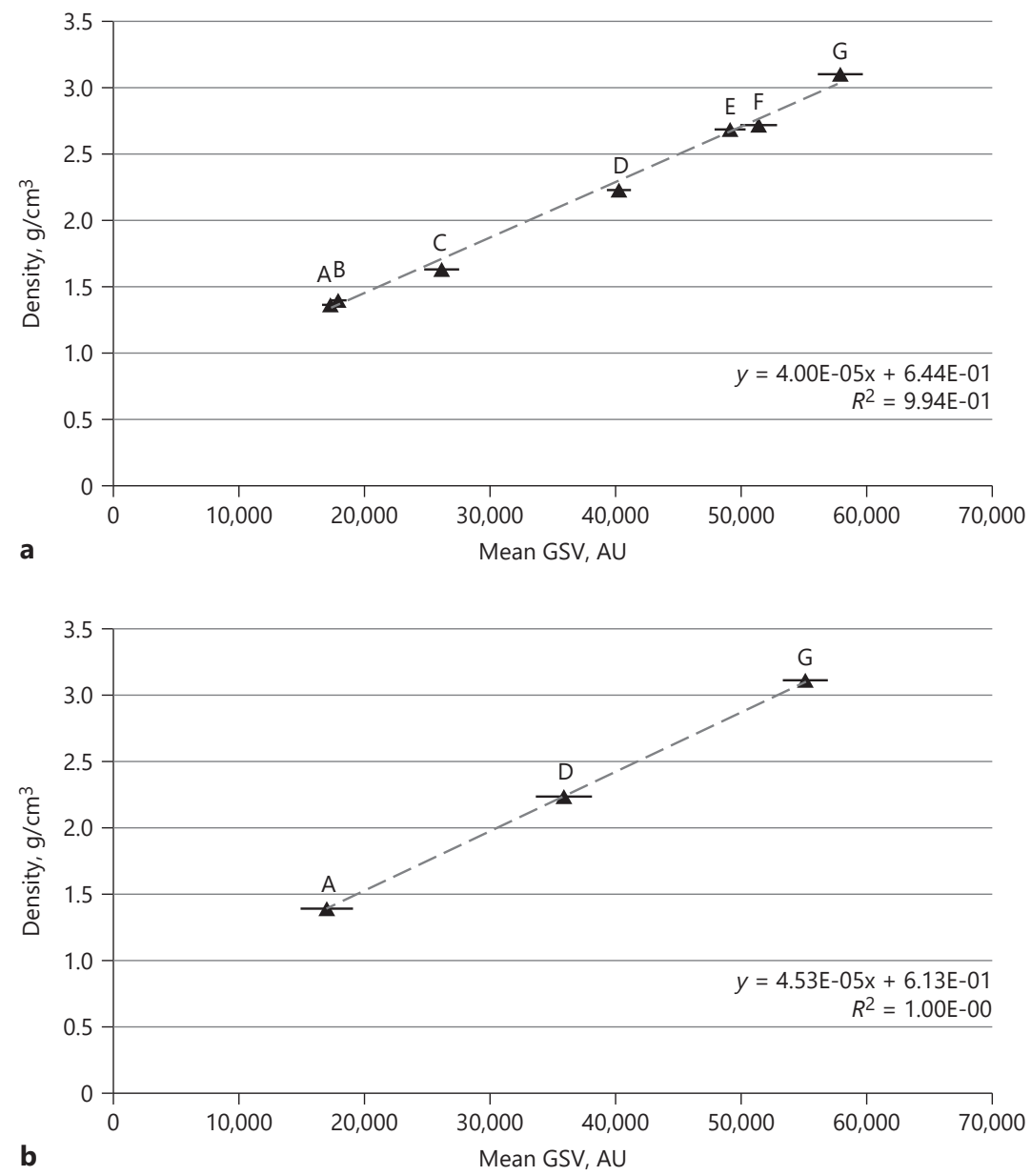

b tings. All $R^{2}$ values at the different voltage settings were $>0.99$. A regression line drawn through best fitting the data points by the least squares regression equation method yielded a regression equation of $y=4.00 \mathrm{E}-05 \mathrm{x}$ $+6.44 \mathrm{E}-01$. Figure $4 \mathrm{~b}$ is a scatter plot that displays the linear relationship for the three chosen CSs. These three CSs yielded $R^{2}$ of 1 . A regression equation of $\mathrm{y}=4.53 \mathrm{E}$ $05 \mathrm{x}+6.13 \mathrm{E}-01$ was yielded.

The estimated density of the bovine enamel disc, based on the obtained calibration function, was $2.48 \mathrm{~g} /$ $\mathrm{cm}^{3}$. The physically measured density of the disc (7.63 $\mathrm{mm}$ in diameter, $1.19 \mathrm{~mm}$ in height, $0.13 \mathrm{~g}$ in weight) was $2.45 \mathrm{~g} / \mathrm{cm}^{3}$. The calculated relative error was $1.2 \%$. Densities of sound enamel in the 10 extracted human premolar teeth, based on the CT-GSVs, ranged from $2.6-3.1 \mathrm{~g} / \mathrm{cm}^{3}$.

\section{Discussion}

In this study, the CSs were chosen based on their densities, which ranged from $1.5-3 \mathrm{~g} / \mathrm{cm}^{3}$ to cover the anticipated density range of sound and carious enamel. As the main objective of this study was to develop an easy method of calibration, ready-made materials were chosen to eliminate the fabrication process of the traditionally used CSs. The examination profile sections of the CSs confirmed the homogeneity and uniformity of the GSV s and the effectiveness of the measures taken to minimize the beam-hardening effect across the seven CSs (Fig. 3a). Non-homogeneity results in variations in GSVs across the CS material, which may introduce errors in the estimation of the true mean GSV of the CS [24]. This might subsequently introduce error in density estimation using such method. 
Consistent with previous studies [19,25], our results showed that as the density of the material increases, the standard deviation of the associated GSV s also increases (Table 1). This can be attributed to the beam-hardening effect, scattering, and noise associated with higher-density materials such as fluorite. With the exception of PPS, the standard deviations of the remaining 6 CSs decreased from fluorite to PET in an expected manner. This is probably due to the fact that PPS, though homogeneous, was slightly granular. However, the fact that its mean GSV fitted the calibration curve led us to include it as a CS. Efforts should be directed at minimizing CT-scan artifacts, which in turn should reduce GSV variations within the material and ensure the reproducibility of GSV. It is worth noting that image de-noising techniques using known filters, such as Gaussian and median filters, were not used in this study. It was our intention to preserve the fine details of the images as the formerly mentioned techniques cause significant blurring of images with subsequent loss of fine details. The use of the "block-matching and three-dimensional method," a method that has been shown to preserve the texture and fine details, may have benefitted in de-noising the micro-CT images in our study [26].

An $R^{2}$ of 0.99 indicated a very high correlation between the mean GSV of each CS and its calculated density. Scans taken at different settings confirmed the reproducibility and stability of this linear relationship independent of the composition of the CS and the voltage applied (Table 2). The regression equation derived enabled us to predict the density of a material based on its average GSV. The CT-estimated density of bovine enamel disc showed high accuracy when compared to the physically measured value. The CT-estimated density of intact human enamel in extracted premolars correlated well with the reported values making this system of CSs valid for enamel caries research. The reported densities of sound enamel in the literature ranged between 2.4 and $3.1 \mathrm{~g} / \mathrm{cm}^{3}[6-9,15,27,28]$.

Potential errors in density measurement using the above calibration method might derive from different sources. The chemical composition of a material is one source. If the material of interest contains some heavy metals, it will probably result in higher CT-GSV than expected. Another source of error is the extrapolation of the calibration function to estimate an unknown material's density outside the density range of the CSs used. Each calibration function is specific to the individual scan and cannot be applied to other scans. Hence, CSs should be scanned with each sample to derive its spe-
Table 1. Physically measured densities and mean GSVs of CSs with standard deviations (SD)

\begin{tabular}{lll}
\hline CS & Density, g/cm ${ }^{3}$ & Mean GSVs (SD), AU \\
\hline Fluorite & 3.1 & $59,979(1,576)$ \\
Aragonite & 2.72 & $52,642(1,239)$ \\
Alabaster & 2.7 & $50,584(973)$ \\
Selenite & 2.24 & $41,634(689)$ \\
PPS & 1.64 & $26,629(1,471)$ \\
Acetal & 1.41 & $18,141(443)$ \\
PET & 1.38 & $17,294(503)$ \\
\hline
\end{tabular}

Table 2. Regression data obtained at different voltage settings using the least squares regression equation method

\begin{tabular}{llll}
\hline Voltage & Slope & Intercept & $R^{2}$ \\
\hline 60 & $5.01 \mathrm{E}-05$ & $5.77 \mathrm{E}-01$ & $9.97 \mathrm{E}-01$ \\
70 & $4.58 \mathrm{E}-05$ & $5.51 \mathrm{E}-01$ & $9.95 \mathrm{E}-01$ \\
80 & $4.22 \mathrm{E}-05$ & $6.45 \mathrm{E}-01$ & $9.95 \mathrm{E}-01$ \\
90 & $4.14 \mathrm{E}-05$ & $6.26 \mathrm{E}-01$ & $9.94 \mathrm{E}-01$ \\
100 & $4.17 \mathrm{E}-05$ & $6.23 \mathrm{E}-01$ & $9.93 \mathrm{E}-01$ \\
110 & $4.00 \mathrm{E}-05$ & $6.44 \mathrm{E}-01$ & $9.94 \mathrm{E}-01$ \\
\hline
\end{tabular}

cific calibration function. CT-scan-associated artifacts such as noise, ring artifacts, scattering, and beam-hardening effects, can also be a source of measurement errors, especially when high-contrast resolution is required. Beam hardening produces a nonlinear signal-todensity relationship, which can affect the accuracy of micro-CT measurements [29]. This effect is more pronounced with higher-density materials. Typical measures to reduce it were employed by applying the beam-hardening correction module, pre-filtration, and through the automatic beam-hardening correction. Ring artifacts were reduced through flat-field correction [30]. To increase the signal-to-noise ratio and to decrease the noise of CT projections, frame averaging was applied. Image de-noising, using the block-matching and three-dimensional method, should be explored in future research related to the study of early enamel lesions. Despite all efforts made to reduce artifacts, the presence of some artifacts is inevitable, and if these artifacts were present at areas of interest, then they will undoubtedly affect measurements. 


\section{Conclusion}

In the current study, seven minerals and polymers were found to be suitable CSs to establish a linear, reproducible calibration function covering the anticipated density range for enamel caries research. Fluorite, selenite, and PET, which best conformed to the calibration function, were chosen as a streamlined calibration set. With copper pre-filtration, beam-hardening correction during reconstruction, frame averaging, and flat-field correction, the derived calibration function accurately predicted the density of enamel based on its average GSV. The developed system of CSs with its derived calibration function is a simple, valid, and reproducible method to quantitate enamel mineral density for caries research.

\section{Acknowledgements}

The authors thank Rudolf Kusy, Shaji Michael, Sreeja Saji, and Merin Lejoe for their technical support.

\section{Statement of Ethics}

Ethical clearance was obtained from Kuwait University/Health Sciences Centre Ethical Clearance Committee (Ref.: VDR/ $\mathrm{EC} / 3332$ ).

\section{Disclosure Statement}

The authors have no conflicts of interest to declare.

\section{Funding Sources}

The project was funded by Kuwait University (Grant No. SRUL01/14).

\section{References}

1 Ten Bosch JJ, Angmar-Månsson B. A review of quantitative methods for studies of mineral content of intra-oral caries lesions. J Dent Res. 1991 Jan;70(1):2-14.

2 Arends J, ten Bosch JJ. Demineralization and remineralization evaluation techniques. J Dent Res. 1992 Apr;71(Spec No):924-8.

3 Wong FS, Willmott NS, Davis GR. Dentinal carious lesion in three dimensions. Int J Paediatr Dent. 2006 Nov; 16(6):419-23.

4 Alkaabi W, AlShwaimi E, Farooq I, Goodis HE, Chogle SM. A micro-computed tomography study of the root canal morphology of mandibular first premolars in an Emirati population. Med Princ Pract. 2017;26(2): 118-24.

5 Wong FS, Elliott JC, Davis GR, Anderson P. $\mathrm{X}$-ray microtomographic study of mineral distribution in enamel of mandibular rat incisors. J Anat. 2000 Apr;196(Pt 3):405-13.

6 Dowker SE, Elliott JC, Davis GR, Wilson RM, Cloetens P. Synchrotron x-ray microtomographic investigation of mineral concentrations at micrometre scale in sound and carious enamel. Caries Res. 2004 Nov-Dec;38(6): $514-22$.

7 Wong FS, Anderson P, Fan H, Davis GR. Xray microtomographic study of mineral concentration distribution in deciduous enamel. Arch Oral Biol. 2004 Nov;49(11): 937-44.

8 Clementino-Luedemann TN, Kunzelmann $\mathrm{KH}$. Mineral concentration of natural human teeth by a commercial micro-CT. Dent Mater J. 2006 Mar;25(1):113-9.
9 Huang TT, Jones AS, He LH, Darendeliler MA, Swain MV. Characterisation of enamel white spot lesions using X-ray micro-tomography. J Dent. 2007 Sep;35(9):737-43.

10 Cochrane NJ, Cai F, Huq NL, Burrow MF, Reynolds EC. New approaches to enhanced remineralization of tooth enamel. J Dent Res. 2010 Nov;89(11):1187-97.

11 Shahmoradi M, Swain MV. Micro-CT analysis of naturally arrested brown spot enamel lesions. J Dent. 2017 Jan;56:105-11.

12 Hahn SK, Kim JW, Lee SH, Kim CC, Hahn $\mathrm{SH}$, Jang KT. Microcomputed tomographic assessment of chemomechanical caries removal. Caries Res. 2004 Jan-Feb;38(1):75-8.

13 Songsiripradubboon S, Hamba H, Trairatvorakul C, Tagami J. Sodium fluoride mouthrinse used twice daily increased incipient caries lesion remineralization in an in situ model. J Dent. 2014 Mar;42(3):271-8.

14 Kierklo A, Tabor Z, Pawińska M, Jaworska M A microcomputed tomography-based comparison of root canal filling quality following different instrumentation and obturation techniques. Med Princ Pract. 2015;24(1):8491.

15 Zou W, Hunter N, Swain MV. Application of polychromatic $\mu \mathrm{CT}$ for mineral density determination. J Dent Res. 2011 Jan;90(1):1830.

16 Elliott JC, Wong FS, Anderson P, Davis GR, Dowker SE. Determination of mineral concentration in dental enamel from X-ray attenuation measurements. Connect Tissue Res. 1998;38(1-4):61-72; discussion 73-9.
17 Nuzzo S, Lafage-Proust MH, Martin-Badosa E, Boivin G, Thomas T, Alexandre C, et al. Synchrotron radiation microtomography allows the analysis of three-dimensional microarchitecture and degree of mineralization of human iliac crest biopsy specimens: effects of etidronate treatment. J Bone Miner Res. 2002 Aug;17(8):1372-82.

18 Nuzzo S, Peyrin F, Cloetens P, Baruchel J, Boivin G. Quantification of the degree of mineralization of bone in three dimensions using synchrotron radiation microtomography. Med Phys. 2002 Nov;29(11):2672-81.

19 Schwass DR, Swain MV, Purton DG, Leichter JW. A system of calibrating microtomography for use in caries research. Caries Res. 2009;43(4):314-21.

20 Willmott NS, Wong FS, Davis GR. An X-ray microtomography study on the mineral concentration of carious dentine removed during cavity preparation in deciduous molars. Caries Res. 2007;41(2):129-34.

21 Cochrane NJ, Anderson P, Davis GR, Adams GG, Stacey MA, Reynolds EC. An X-ray microtomographic study of natural white-spot enamel lesions. J Dent Res. 2012 Feb;91(2): $185-91$.

22 Schweizer S, Hattendorf B, Schneider P, Aeschlimann B, Gauckler L, Müller R, et al. Preparation and characterization of calibration standards for bone density determination by micro-computed tomography. Analyst (Lond). 2007 Oct;132(10):1040-5.

$23 \mathrm{He} \mathrm{LH,} \mathrm{Standard} \mathrm{OC,} \mathrm{Huang} \mathrm{TT,} \mathrm{Latella} \mathrm{BA,}$ Swain MV. Mechanical behaviour of porous hydroxyapatite. Acta Biomater. 2008 May; 4(3):577-86. 
24 Postnov AA, Vinogradov AV, Van Dyck D, Saveliev SV, De Clerck NM. Quantitative analysis of bone mineral content by $\mathrm{x}$-ray microtomography. Physiol Meas. 2003 Feb; 24(1):165-78.

25 Zou W, Gao J, Jones AS, Hunter N, Swain MV. Characterization of a novel calibration method for mineral density determination of dentine by X-ray micro-tomography. Analyst (Lond). 2009 Jan;134(1):72-9.
26 Shahmoradi M, Lashgari M, Rabbani H, Qin J, Swain M. A comparative study of new and current methods for dental micro-CT image denoising. Dentomaxillofac Radiol. 2016; 45(3):20150302.

27 Weidmann SM, Weatherell JA, Hamm SM. Variations of enamel density in sections of human teeth. Arch Oral Biol. 1967 Jan;12(1): 85-97.

28 Dowker SE, Elliott JC, Davis GR, Wassif HS Longitudinal study of the three-dimensional development of subsurface enamel lesions during in vitro demineralisation. Caries Res. 2003 Jul-Aug;37(4):237-45.
29 Hammersberg P, Mångård M. Correction for beam hardening artefacts in computerised tomography. J Xray Sci Technol. 1998 Jan;8(1): 75-93.

30 Sijbers J, Postnov A: Reduction of ring artefacts in high resolution micro-CT reconstructions. Phys Med Biol. 2004;49(14):N247-253. Available from: https://doi.org/10.1088/00319155/49/14/N06. 